\title{
COVID-19 and vascular diseases
}

\section{(1)Ljiljana Banfić*}

University of Zagreb School of Medicine, Zagreb, Croatia
RECEIVED:

December 5, 2020

ACCEPTED:

December 18, 2020

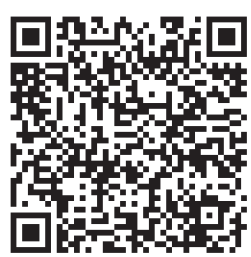

KEYWORDS: cardiovascular diseases, venous thrombosis, COVID-19.

CITATION: Cardiol Croat. 2021;16(1-2):69. | https://doi.org/10.15836/ccar2021.69

*ADDRESS FOR CORRESPONDENCE: Ljiljana Banfić, Medicinski fakultet, Šalata 2, HR-10000 Zagreb, Croatia. / Phone: +385-98-1710329 / E-mail: ljiljanabanfic@yahoo.com

ORCID: Ljiljana Banfić, https://orcid.org/0000-0002-4538-8980

\section{IIIIIIIIIIIIIIIIIIIIIIIIIIIIIIIIIIIIIIIIIIIIIIIIIIIIIIIIIIIIIIIIIIIIIIIIIIIIIIIIIIIIIIIIIIIIIIIIIIIIIIIIIIIIIIIII}

COVID-19 is systemic disease that affects human cells by binding to angiotensin converting enzyme 2 (ACE2) receptor and is considered as mild disease for the most patients affected by virus. About $15 \%$ of patients could develop severe symptoms and $5 \%$ of them require intensive care unit treatment. The pathogenesis of disease is characterized as immunothrombosis with proinflammatory and procoagulant state. Hypercoagulability, microangiopathy, venous thromboembolism (VTE) and arterial thrombosis affects patients with underlying cardiovascular risk and vascular disease as they are more likely to require critical care because of increased likelihood for severe and very severe forms of COVID-19 infection. Thromboprophylaxis with DOACs or LMWH is recommended because of increased vascular patient vulnerability. Compared to the patient with a history or actual deep vein thrombosis and pulmonary embolism arterial thrombosis occur less frequently and has lower mortality rate. The VAS-European Independent Foundation in Angiology/Vascular Medicine ${ }^{1}$ published guidance for the management of COVID patients with vascular diseases and cardiovascular risk factors. VAS recommendation clarifies the need for identification of patients with vascular diseases in COVID-19 infection and preventive measures in hospital and outpatient setting. The important role of primary health care network and eHealth technology is to recognize and identify vascular patients with COVID. Family doctors should promote adherence to the antithrombotic therapy (Aspirin, Clopidogrel, Prasugrel, Ticagrelor), statins and antihypertensive drugs because of their protective potential during COVID-19 infection. The great attention is focused on thromboprophylaxis with intermediate doses of LMWH in hospitalized patients. DOACs or LMWH are recommended in postdischarged period for up to 40 days if IMPROVE-D-dimer score is $>4$. The scoring is suggested as useful tool in patients selection for possible prolonged prophylaxis with DOACs: rivaroxaban $10 \mathrm{mg}$ OD, and betrixaban $80 \mathrm{mg}$ OD, or LMWH at weight adjusted prophylactic dose. Guidance document published by VAS is useful frame for care of vascular patient and COVID-19 infection, although proposed recommendations has a low grade of evidence as randomized clinical trials are still lacking.

LITERATURE IIIIIIIIIIIIIIIIIIIIIIIIIIIIIIIIIIIIIIIIIIIIIIIIIIIIIIIIIIIIIIIIIIIIIIIIIIIIIIIIIIIIIIIIIIIIIIIIIIIIIIII

1. Gerotziafas GT, Catalano M, Colgan MP, Pecsvarady Z, Wautrecht JC, Fazeli B, et al; Scientific Reviewer Committee. Guidance for the Management of Patients with Vascular Disease or Cardiovascular Risk Factors and COVID-19: Position Paper from VAS-European Independent Foundation in Angiology/Vascular Medicine. Thromb Haemost. 2020 Sep 13. Online ahead of print. https://doi.org/10.1055/s-0040-1715798 